\title{
Weinfurter, Stefan, Das Reich im Mittelalter. Kleine deutsche Geschichte von 500 bis 1500
}

Pierre Monnet

\section{OpenEdition}

Journals

Édition électronique

URL : http://journals.openedition.org/ifha/1665

DOI : 10.4000/ifha.1665

ISSN : 2198-8943

Éditeur

IFRA - Institut franco-allemand (sciences historiques et sociales)

Référence électronique

Pierre Monnet, « Weinfurter, Stefan, Das Reich im Mittelalter. Kleine deutsche Geschichte von 500 bis 1500 », Revue de l'IFHA [En ligne], Date de recension, mis en ligne le 01 janvier 2008, consulté le 22 septembre 2020. URL : http://journals.openedition.org/ifha/1665; DOI : https://doi.org/10.4000/ifha 1665

Ce document a été généré automatiquement le 22 septembre 2020.

(C)IFHA 


\title{
Weinfurter, Stefan, Das Reich im Mittelalter. Kleine deutsche Geschichte von 500 bis 1500
}

\author{
Pierre Monnet
}

1 S.W., professeur à l'Université de Heidelberg, est bien connu des médiévistes pour ses travaux sur les Saliens et plus particulièrement sur Henri II. Mais il a également beaucoup œuvré pour mieux faire comprendre ce qu'était le Saint-Empire médiéval, « Heilig, römisch, deutsch », "sacré, romain, allemand ». On le sait, l'appellation de Saint-Empire romain germanique ( Heiliges Römisches Reich deutscher Nation ») est très tardive : elle s'impose en effet seulement dans la seconde moitié du XVe s., soit à la toute fin de la période que les césures académiques tiennent pour " médiévale ». C'est cette chronologie, 500-1500, que retient pourtant S.W., se demandant justement comment l'on est passé du royaume franc de Clovis à l'Empire germanique de Maximilien Ier. Dès lors, c'est bien l'Empire, comme construction politique, religieuse et territoriale qui devient par excellence un objet médiéval. Ce n'est certes pas la première synthèse proposée sur un tel sujet, et tout porte même à croire que l'écriture d'un tel livre constitue un exercice obligé pour de nombreux médiévistes allemands. Mais il n'est pas fréquent de disposer d'un ouvrage d'une telle ampleur et en même temps d'une telle profondeur de vues. Les étapes de ce méta-récit (l'Empire n'est-il pas la Meistererzählung par excellence de l'histoire allemande ?) sont connues et l'auteur les respecte : les origines franques, l'Empire carolingien, la refondation romaine des Ottoniens, l'articulation complexe entre Empire, royauté et royaumes sous les Saliens, la sacralisation sous les Staufen et la progressive séparation entre idée d'Empire et gouvernement d'Empire, l'inflexion nationale de la fin du Moyen Âge sous la double influence du jeu territorial entre les pays allemands (que règle en partie la Bulle d'Or de 1356) et des réformes concomitantes de l'Église et de l'Empire. En récapitulant par quels biais chaque couche impériale, romaine, sacrée et germanique se superpose, mais aussi s'articule différemment en donnant à l'une ou à l'autre un poids plus ou moins important, S.W. raconte le passage non pas linéaire mais fragmenté des Francs aux Allemands sur tout un millénaire. Loin de toute téléologie, le récit tente de sentir les 
bifurcations, les impasses et d'imaginer ce qu'aurait pu être l'histoire allemande, conséquemment l'histoire française, et partant l'histoire européenne, si Charlemagne n'avait pas fait le choix du couronnement romain, si Otton avait été battu à la bataille du Lechfeld, si les deux universaux, le pape et l'empereur, ne s'étaient pas en partie neutralisés... Des charnières importantes sont fixées par l'auteur : celle du XIIe s. au cours duquel l'Empire sacré devient une entité en soi, peu à peu réservée aux dynasties allemandes qui le gouvernent; le XIIIe s. également au cours duquel la langue allemande concurrence (et non remplace) et enrichit le latin.

2 Écrit dans un style clair et alerte, sans notes de bas de page (une performance pour un livre d'histoire allemand !) mais pourvu d'une bibliographie actuelle, de tableaux généalogiques et de cartes, cette synthèse est plus qu'un petit précis d'histoire allemande au Moyen Âge, elle est une véritable réflexion sur la formation et l'évolution d'une forme européenne du pouvoir et de la société, un Empire qui dut apprendre tôt la souveraineté partagée et la cohabitation d'une grande variété de droits, de dialectes, de territoires et de populations au sein d'un ensemble aux frontières sans cesse mouvantes. À ce titre, la réflexion reste d'une grande actualité.

Pierre Monnet (École des Hautes Études en Sciences Sociales, Paris) 